УАK 342.7

ББК 67.4003

DOI 10.22394/1682-2358-2019-2-20-29

N.V. Malyavkina, Candidate of Sciences (Law), Docent of Department of constitutional and municipal law Central Russian Institute of Management, Branch of Russian Presidential Academy of National Economy and Public Administration

O.E. Aleksikova, Candidate of Sciences (Law), Docent of the Constitutional and Municipal Law Department, Central Russian Institute of Management, Branch of Russian Presidential Academy of National Economy and Public Administration

\section{FEATURES \\ OF REALIZATION \\ OF CONSTITUTIONAL \\ RIGHT OF CITIZENS \\ OF THE RUSSIAN \\ FEDERATION \\ TO THE APPEAL \\ TO PUBLIC \\ AUTHORITIES}

Features of realization of constitutional right to appeal to public authorities are studied. Special attention is paid to problems of legal regulation of the relations on realization of this right on the basis of which separate recommendations on the improvement of the legislation in force in the given legal field are formulated.

Key words and word-combinations. right to appeal, collective and individual appeals, restriction of the right to appeal.
Н.В. Малябкина, кандидат юридических наук, дочент кафедрь конституиионного и муниципального праља Среднерусского института управления - филиала Российской академии народного хозяйства и государственной службь при Президенте РФ (email: nata-m-orel@mail.ru)

O.E. Алексикова, кандидат юридических наук, дочент кафедрог конституционного и муниципального права Среднерусского института управления - филиала Российской академии народного хозяйства и государственной службь при Президенте РФ (email: aloe30@mail.ru)

\section{ОСОБЕННОСТИ РЕААИЗАЦИИ КОНСТИТУЩИОННОГО ПРАВА ГРАЖААН РОССИЙСКОЙ ФЕАЕРАЦИИ НА ОБРАЩЕНИЕ В ОРГАНЫ ПУБАИЧНОЙ ВААСТИ}

Аннотация. Исследуются особенности реализации конституционного права на обращение в органы публичной власти. Особое внимание уделяется проблемам правового регулирования отношений по реализации данного права, на основе которых формулируются отдельные рекомендации по совершенствованию действующего в данной правовой области законодательства.

Ключевые слова и словосочетания: право на обращение, коллективные и индивидуальные обращения, ограничение права на обращение.

B мее значимых мест в общей системе конституционных прав и свобод человека и 
гражданина занимает право граждан Российской Федеращии на обращение в органы публичной власти. Несмотря на достаточно Алительную историю сушествования данного права в отечественной правовой системе, практически с момента образования Российского государства, в течение которого оно претерпевало разцичные изменения в зависимости от происходящих процессов на каждом конкретном историческом этапе формирования российской государственности, его опосредованное конституџионное закрепление впервые получено в Конститущии СССР 1977 г., где за советскими гражданами закреплялся ряд существенных прав. Во-первых, право участвовать как в управлении государственными и общественными делами, так и в обсужАении и принятии законов и решений, имеющих общегосударственное и местное значение (ст. 48). Во-вторых, право внесения предможений в органы государственной власти и общественные организации об улучшении их деятельности, а также право критиковать их недостатки в работе (ст. 49). На должностные миџа возмагалась обязанность по рассмотрению предложений и заявлений граждан, Ааче на них ответов и принятию необходимых мер в установленные законодательством сроки. Кроме того, в ст. 58 советской Конституции было закреплено право советских граждан обжаловать действия государственных и общественных организаций, а также должностных миц. В случае совершения должностными миџами действий, противоречащих закону, ушемляюших права граждан мибо совершенных с нарушением закона, граждане СССР имели возможность обжаловать их в суде в установленном законом порядке [1]. ОАнако, несмотря на эти конституџионные установления, на данном историческом этапе конституционного закрепления не получимо такое важное право граждан, как обращение в органы публичной власти с целью защиты собственных интересов.

В действующей Конституции РФ право граждан Российской Федерации обращаться в органы публичной власти закреплено в ст. 33 [2]. Предоставменное государством право, во-первых, позволяет российским гражданам свободно выражать собственное мнение при обрашении в органы публичной власти; во-вторых, дает им возможность участвовать в управлении делами государства, выступая при этом одним из важнейших юридических среАств доведения до органов власти интересов и потребностей насемения Российской Федерации.

Определяя место конституционного права граждан Российской ФеАерации на обращение в органы публичной власти в системе прав и свобод человека и гражданина, следует особое внимание обратить на его тесную взаимосвязь с рядом других важных конституционных прав и свобод, а именно:

- с закрепленной в ч. 1 ст. 29 Основного Закона России в отношении кажАого свободой мысли и слова - возможностью свободно выражать собственное мнение как устно, так и письменно, обращаясь в органы пубцичной власти, Аавая собственную оџенку в отношении деятельности государства в цемом и работы того или иного органа публичной власти в частности, критикуя или одобряя ее [3, с. 15]; 
- закрепленным на конституционном уровне в ч. 4 ст. 29 правом на информацию, а именно, свободу ее поиска, получения, передачи, производства и распространения мюбым законным способом, если только это никаким образом не связано с разглашением какой-либо тайны - государственной и охраняемой законом иной тайны;

- конституционным правом, нашедшим законодательное закрепление в ст. 31 Основного Закона РФ, - правом российских граждан собираться мирно, без оружия, проводить собрания, митинги, Аемонстрации, шествия и пикетирования Аля привлечения внимания органов государственной власти к какому-цибо общественно значимому вопросу. Участники проводимых мероприятий надеются на удовцетворение заявленных требований и получение положительного результата после проведенных мероприятий;

- правом каждого защищать свои права и свободы всеми не запрещенными законом способами (ч. 2 ст. 45 Основного Закона РФ). С этой целью гражжане обращаются в органы публичной власти, которые, в свою очередь, с помощью компетентных Аействий обязаны защищать и охранять конституционные права и свободы человека и гражданина. Степень общественного Аоверия граждан органам пубцичной вцасти напрямую зависит от заинтересованности вцастных органов быстро и качественно реагировать на такие обращения.

Конститущионная норма, закрепляющая право граждан Российской Федерации на обращение в органы публичной власти, получила дальнейшую подробную регламентацию в Федеральном законе «О порядке рассмотрения обращений граждан Российской Федерации», где определены виды, порядок и сроки рассмотрения обращений и т.п. В ст. 4 указанного нормативного правового акта обращение гражданина определено в качестве, во-первых, предложения, заявления или жалобы, направленных в письменной форме или в форме электронного Аокумента в органы пубцичной вмасти; во-вторых обращения гражданина, осуществцяемого в устной форме [4] .

Анализ действующего законодательства и различных источников юридической митературы позволяет классифицировать все обращения граждан в органы пубцичной вцасти по ряду оснований:

1) в зависимости от количественного состава субъектов (граждан, обращающихся в органы пубцичной власти) такие обращения могут быть как индивидуацьными, так и комлективными;

2) в зависимости от облекаемой формы выдемяют три разновидности обращений гражжан: устные, письменные, электронные;

3) в зависимости от адресата, которому направцяется данное обращение: в органы государственной вмасти; в органы местного самоуправления; Аолжностным миџам государственных и муниципальных учреждений и иных организаций, на которые возложено осуществление публично значимых функций;

4) в зависимости от содержательной направленности выделяют несколько видов обращений граждан. 
Во-первых, предложения, представмяюшие собой устные или письменные рекомендации по совершенствованию действующего законодательства, деятельности органов пубцичной власти, развитию общественных отношений, улучшению соџиально-экономической и иных сфер деятельности государства и общества. Характерной особенностью данной разновидности обращений является то, что они не связаны с нарушением прав обращающегося, поскольку, как правияо, содержат предложения с целью внесения изменений в существующий порядок работы органов публичной власти и носят рекомендательный характер. Именно благодаря применению данной разновидности обрашений граждане могут свободно выражать собственное мнение в отношении государственной политики, а также проводимых в обществе и государстве преобразований. Предложения явмяются каналом обратной связи между государством и обществом, в них содержится информация о несовершенстве и недостатках государственного управления. С помощью преАложений граждане могут попытаться повлиять на принятие решений органами публичной власти. Изучая и обобшая предложения, органы публичной власти при составлении законопроектов учитывают общественное мнение по тому или иному вопросу.

Во-вторых, заявления, представляющие собой мибо просьбу гражданина о содействии в реализации конституционных прав и свобод его или Аругих миџ, Аибо сообшение о нарушении норм действуюшего законодательства, не-

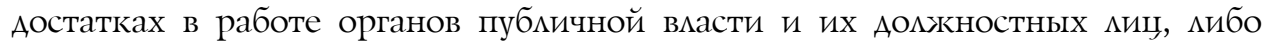
критику их деятельности. Запрещается преследование граждан, выступающих с критикой деятельности органов или должностного миџа. Заявления призваны восстанавливать ияи защищать права и свободы граждан и их законных преАставителей.

В-третьих, жалобы - просьбы гражданина о восстановлении или защите его нарушенных прав, свобод или законных интересов цибо прав, свобоА или законных интересов Аругих миџ. Как показывает современная практика, жалоба явмяется наиболее распространенным видом обрашений граждан, позволяющим добиться справедливости при нарушении прав и свобод гражАан. Именно данный вид обрашений играет первостепенную роль в защите основных прав и свобод чемовека и гражданина в случаях неправомерных Аействий (бездействий) органов публичной власти. Характерной особенностью реализаџии права на обращения путем подачи жалобы является то, что гражАане обрашаются в органы публичной власти ици к домжностным Аицам с конкретным требованием или просьбой о восстановмении их нарушенных прав или свобол, при этом обрашение в виде жалобы может быть совершено как в устной, так и в письменной форме. Письменная (Аокументальная) форма имеет очевидные преимущества, поскольку в ней фиксируются факты и доводы, излагаемые заявителем, что облегчает принятие решения дАя дачи квамифиџированного ответа.

Обращение гражАан в органы пубцичной власти, индивидуацьное ици коммективное, связано с выражением ими своего мнения по разцичным сферам жизнедеятельности, которое они и пытаются донести до соответс- 
твующего властного органа. Подобная практика подтверждает мнение А.А. Аворак о том, что обращения явмяются определенным информационным каналом между органами государственной власти и гражданами по выявлению общественного мнения. Получение ответов на обращения и проведение определенных действий со стороны органов публичной власти обеспечивает взаимодействие между государством и обществом и свидетельствует о реакщии государства на сигналы от граждан, нуждающихся в помощи и подАержке [5] .

Сегодня наблюдается устойчивая тенденция к увеличению потока обращений, основная часть которых связана с повседневными проблемами граждан. Множество обрашений касается нарушений индивидуальных (личных - гражАанских и политических прав человека) и коммективных (социально-экономических) прав человека и гражданина, а также реализации политических прав гражАан, включая право их участия в управлении делами государства, которые в совокупности с индивидуамьными и комективными правами составмяют в Российской Федерации основу правового статуса кичности.

Сущность права на обращение проявмяется прежде всего в обратной связи межАу органами власти и гражданами по выявлению общественного мнения, выраженного в соџиальных потребностях о качестве и недостатках работы органов публичной власти. Несмотря на достаточно подробную регламентацию отношений по реализации гражАанами исследуемого конституџионного права, в указанной правовой области существует множество неразрешенных проблем.

ОАна из них связана с определением субъектного состава данных отношений. Исходя из буквального толкования норм ст. 33 Основного Закона РФ и ст. 2 Федерального закона «О порядке рассмотрения обрашений граждан Российской Федерации» следует, что субъектами, надеменными правом на обрашение, являются только российские граждане. ОАнако в положениях Конвенции о защите прав человека и основных свобол, это право в равной мере принадмежит также и гражданам иностранных государств, и миџам без гражданства [6].

Спещифика юридического статуса субъекта права на обращение состоит в том, что в отношении него не устанавливается никаких возрастных ограничений, а это позволяет утверждать, что возраст граждан не влияет на реализаџию данного права. Соответственно конституџионному принџипу правового равенства несовершеннолетние также обладают указанным правом. В подтверждение следует обратиться к норме ст. 24 Международного пакта о гражАанских и политических правах, в которой закрепляется, что каждый ребенок имеет право на необходимые меры защиты со стороны его семьи, государства и общества без всякой дискриминаџии по расовому признаку, цвету кожи, полу, языку, религии, наџиональному ици соџиальному происхождению, имущественному положению [7]. Согласно нормам Семейного кодекса РФ, представлять интересы детей должны их родители или иные законные представитеми [8]. Если они не желают или не имеют возможности это сАелать, то в случае нарушения прав дети самостоятель- 
но могут обращаться в органы опеки и попечительства, которые Аолжны обеспечивать и защищать интересы ребенка, в том числе оказывая помощь в оформлении таких обращений и представцяя интересы несовершеннолетнего ребенка в суде.

В случае наличия у человека психического расстройства право на обращение также не подмежит ограничению. Аанный вывод следует из нормы ст. 5 Закона РФ «О психиатрической помощи и гарантиях прав граждан при ее оказании», где установцено, что страдающие психическими расстройствами мица обладают всеми предусмотренными на конституционном и федераль-

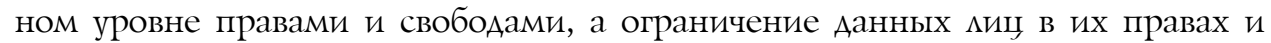
свободах Аопустимо мишь в законодательно предусмотренных случаях, причем не Аопускается ограничение их прав и свобод только мишь на основании психиатрического диагноза. Указанные мица наделены правом на оказание им помощи со стороны адвоката, законного представителя или иного мица в установценном законом порядке [9].

Законодательство не содержит прямых ограничений реализации права на обращение в органы государственной власти дия недееспособных гражАан. Его единственное законодательное ограничение - это ограничения по

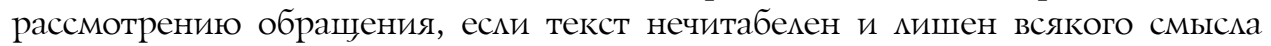
(ст. 11 Федерального закона «О порядке рассмотрения обращений граждан Российской Федерации»). Обращения, не подАающиеся истолкованию, как правицо, сигнацизируют о психическом состоянии заявителя; в этом случае уполномоченные органы могут уведомить заявитемя о неясности обращения и объяснить невозможность его разрешения. Это свидетельствует о наличии на законодательном уровне некоторых ограничений права на обращения недееспособных миџ. В цемях исключения спорных ситуаџий в подобных случаях

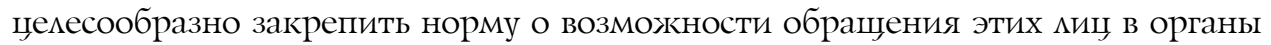
пубцичной власти через своих законных представителей путем внесения в ч. 1 ст. 2 Федерального закона «О порядке рассмотрения обращений граждан Российской Федерации» после слов «граждане имеют право обращаться кично» Аополнения: «а также через своих законных преАставителей», как это сделано в Фелеральном законе «Об опеке и попечительстве» в отношении недееспособных миџ, участвующих через своих законных преАставителей в гражданскоправовых слелках.

Еще одна проблема касается правового закрепления на законодательном уровне возможности обращения граждан в органы государственной вмасти как в индивидуальной, так и в комлективной форме. Анализ данных форм обращений показывает, что закрепляя возможность комективного обращения гражкаан Российской Федерации в органы публичной власти, законодатель не регламентирует отдельно Аанную форму обращений, в отличие от индивидуальной (например, ст. 13 «Аичный прием граждан»). При прочтении текста Федерального закона «О порядке рассмотрения обращений граждан Российской Федерации» складывается впечатление, что индивидуальным обращениям удемяется больше внимания. Комлективные обращения по многим актуальным вопросам нередко воплощаются в форму петиций, однако такая 
форма обращений не получила законодательного закрепления. Петиция по своему содержанию явмяется откликом общественности на реформы, связанные с Ауховным, политическим, экономическим и социальным содержанием, изменяющим существенный укмаА общественных отношений. Это, скорее, требование проведения реформ по изменению законодательства или реакция граждан на проводимые государством реформы, нарушающие интересы граждан. Отличием петиции от иных форм обращений явмяется сбор подписей в подАержку обращения, но в силу того, что данная форма не регмаментирована законодательством, количество подписей, необходимое для признания комлективного обрашения петицией, не установлено. По нашему мнению, петиция как одна из разновидностей обрашения граждан в органы публичной власти Аолжна быть мибо закреплена в Федеральном законе «О порядке рассмотрения обращений граждан Российской Федерации» наряду с предложениями, заявлениями и жалобами, мибо регламентирована специальным законом, который подробно урегулирует данные отношения, в частности определив количество подписей, необходимое Аля признания колмективного обращения петиџией и соотнесенное с Аолей граждан, проживающих на определенной территории, от населения которой направляется такое обращение [10].

Возникновение следующей проблемы связано с тем, что многие гражАане, не обладая спеџиальными познаниями относительно компетенции того или иного органа государственной власти, не всегда могут самостоятельно определить инстанцию при подаче обрашения. По Аанной причине часто затягивается срок его рассмотрения, поскольку прежде чем обращение попадет по назначению, оно может пройти через мишние инстанции. Эффективность направленных обрашений была бы намного выше при подаче сразу по месту рассмотрения. Кроме того, нередко обращения направмяются в коммегиамьные и совещательные органы или даже институты, которые в своей работе не занимаются рассмотрением обращений граждан. Типичным примером явцяются Правительство РФ и Совет безопасности РФ. Следовательно, переА тем, как направить обращение по месту назначения, заявителю необходимо зайти на официальный сайт органа власти и ознакомиться с его направлениями деятельности и полномочиями, а также уточнить порядок рассмотрения обрашений. Положительным представляется опыт приемных при органах публичной власти, которые проводят Ани открытых Аверей, гАе объясняют гражданам, в какие конкретно органы следует обрашаться по интересующему вопросу.

Достаточно проблемным сегодня явмяется вопрос о соблюдении установменных законодательством сроков рассмотрения обрашений гражАан, поступивших в органы публичной власти. Законодательно установмена общая норма, согласно которой ответ на обращение должен быть дан в течение тридџати Аней, а в исключительных случаях - в течение двадџати Аней с момента его регистрации (письменные обрашения, поступившие высшему должностному мицу субъекта РФ и содержашие информацию о фактах возможных нарушений российского законодательства в сфере миграции). В некоторых слу- 
чаях руководитель органа государственной власти, получившего обращение, или должностное миџо могут увеличить срок рассмотрения обращения, но не более чем на тридцать дней, Аля чего заявителю направляется уведомление о продлении срока на рассмотрение его обращения с указанием причины (ст. 12 Федерального закона «О порядке рассмотрения обрашений граждан Российской Федерации»).

Безусловно, продолжительный периоА рассмотрения обращений не способствует эффективности работы органов публичной власти и препятствует реацизации конституционных прав, свобод и законных интересов субъектов отношений по реализаџии права на обрашение, поэтому установменные на законодательном уровне сроки должны на практике не увеличиваться, а сокращаться. Примечателен опыт ряда субъектов Федерации, в законоАательстве которых установлены дополнительные гарантии по реализации права граждан на обращения; одна из них связана с сокращением сроков рассмотрения обрашений граждан. В законодательстве Нижегородской и Московской областей содержатся нормы, значительно сокращающие сроки рассмотрения отдельных обращений граждан, но причины, по которым могут приниматься подобные решения, законом не установлены, что может создавать определенные трудности в правоприменительной практике. Вместе с тем данный положительный опыт должен быть учтен не только на региональном, но и на федеральном государственном уровне. Цемесообразным представляется внесение изменений в Федеральный закон «О порядке рассмотрения обращений граждан Российской Федераџии» относительно безотлагательного рассмотрения обращений граждан, в которых содержатся сведения о чрезвычайном характере тех или иных жизненных обстоятельств.

Существенным недостатком действующего в исследуемой правовой области законодательства является отсутствие санкций за превышение срока рассмотрения обращения или за отсутствие ответа на него. В ст. 5.59 действующего Кодекса Российской Федераџии об административных правонарушениях устанавливается ответственность за нарушение порядка рассмотрения обращений граждан в виде наложения административного штрафа в размере от 5 до 10 тыс. рублей, но только в отношении домжностных Аиџ органов пубцичной власти, государственных и муниџипааьных учреждений и иных организаций, на которые возможкено осуществление публично значимых функщий [11]. В Аанной административно-правовой норме не упоминается об ответственности самих органов публичной власти за подобного рода нарушения, что, на наш взгляА, явмяется большой законодательной недоработкой, создающей на практике немало проблем.

Предусмотренные ст. 5.59 Кодекса Российской Федеращии об административных правонарушениях дека возбуждаются прокурором (ч. 1 ст. 28.4). Следовательно, заявление о привлечении конкретного должностного Аиџа к административной ответственности по этой статье потерпевшему необходимо подавать на имя соответствуюшего прокурора. При нарушении порядка и сроков рассмотрения обращений пострадавшее киџо имеет право потребо- 
вать возмещения убытков и компенсации морального вреда, причиненных ему незаконным действием (бездействием) органов публичной власти и их Аолжностными мицами, обратившись в суА.

Применительно к преАмету Аанного исследования актуацьным явцяется и вопрос, связанный с отсутствием на законодательном уровне перечня случаев привлечения гражданина-заявителя к рассмотрению его обращения. В соответствии с положениями ст. 10 Федерацьного закона «О порядке рассмотрения обращений граждан Российской Федерации», поступившее в органы пубцичной власти обращение в случае необходимости может рассматриваться с участием заявителя, однако законодатель не устанавцивает, в каких именно случаях заявитель привлекается к рассмотрению его обращения. Более того, непонятно, может ми гражданин самостоятельно определять необходимость своего участия в рассмотрении обращений и выступать с соответствующей инициативой. В Аействующем законодательстве Аанный вопрос не урегулирован, но Аля повышения открытости и прозрачности проџедуры рассмотрения обращения следует на законодательном уровне предусмотреть право заявителя самостоятельно определять необходимость собственного участия в процессе.

Таким образом, на основе проведенного исследования можно выделить основные признаки исследуемого конституционного права граждан Российской Фелерации:

во-первых, неотъемлемость права на обращение, которое является конституционным и принадлежит человеку от рождения. Компетентные органы обязаны ответить на полученное обращение, за искцючением случаев, предусмотренных федеральным законодательством;

во-вторых, конститущионное право на обращение явцяется отправной точкой дмя реализации юридических прав и свобод, закрепленных в иных нормативных актах (в частности, в аАминистративном праве предусмотрено право на обжалование неправомерных действий и решений со стороны органов пубцичной вцасти);

в-третьих, реализаџия данного права происходит с помощью подачи устного или письменного обращения в форме заявления, преАложения ици жалобы;

в-четвертых, обращения граждан могут принимать индивидуальную и комлективную формы, причем целью индивидуального обрашения явмяется реализация определенного права конкретного миџа или его семьи, а целью комективного обращения - пубцичный интерес, удовметворение которого связано с гарантией существования всего общества;

в-пятых, право на обращение применяется в целях защиты и реализации прав, свобод и законных интересов человека и гражданина и является способом осуществления таких прав и свобод посредством выражения собственной позиции по конкретному вопросу, участия в управлении делами государства и Аоведения до вцасти интересов и потребностей граждан.

Все указанные признаки позволяют сформулировать следующее определение: право граждан Российской Федерации на обращение в органы публичной 
власти представляет собой неотъемлемое право гражданина Российской Федерации непосреАственно или через преАставителей обращаться в устной или письменной форме индивидуально или комлективно в компетентные органы власти, уполномоченные реализовывать, защищать и охранять конституционные права и свободы чемовека и гражданина, а в особых случаях - и интересы иных $и ц ц$.

\section{Библиографический список}

1. Конституция СССР от 7 окт. 1977 г. // Ведомости ВС СССР. 1977. № 41. Ст. 617 (утратила силу).

2. Конституция РФ (с учетом поправок, внесенных Законами РФ о поправках к Конституции РФ от 21 июля 2014 г. № 11-ФКЗ) // СЗ РФ. 2014. № 31. Ст. 4398.

3. Скрябина M.B. Реализация конституционного права граждан на обращения в органы публичной власти: дис. ... канд. юрид. наук. СПб, 2007.

4. О порядке рассмотрения обращений граждан Российской Федерации: Федер. закон от 2 мая 2006 г. № 59-Ф3 (в ред. от 27 дек. 2018 г.) // СЗ РФ. 2006. № 19. Ст. 2060; 2018. № 53, ч. 1. СТ. 8454 .

5. Дворак А.А. Реализация конституционного права граждан на обращения в Российской Федерации: дис. .... канд. юрид. наук. М., 2003.

6. Конвенция о защите прав человека и основных свобод от 4 нояб. 1950 г.) // СЗ РФ. 2001. № 2. Ст. 163.

7. Международный пакт о гражданских и политических правах (Нью-Йорк, 16 дек. 1966 г.) // Библиотечка «Российской газеты». 1999. Вып. № 22-23.

8. Семейный кодекс РФ от 29 дек. 1995 г. № 223-ФЗ (в ред. от 18 марта 2019 г.) // СЗ РФ. 1996. № 1. Ст. 16; 2019. № 12. Ст. 1225.

9. О психиатрической помощи и гарантиях прав граждан при ее оказании: Закон РФ от 2 июля 1992 г. № 3185-1 (в ред. от 19 июля 2018 г.) // СЗ РФ. 1992. № 33. Ст. 1913; 2018. № 30. Ст. 4548.

10. Нудненко Л.А. Концепция Федерального закона «О петициях граждан Российской Федерации». URL: https://wiselawyer.ru

11. Кодекс РФ об административных правонарушениях от 30 дек. 2001 г. № 195-ФЗ (в ред. от 1 апр. 2019 г.) // СЗ РФ. 2002. № 1, ч. 1. Ст. 1; 2019. № 14, ч. 1. Ст. 1465. 